\title{
SIX SIGMA SEBAGAI ALAT PENGENDALIAN MUTU PADA HASIL PRODUKSI KAIN MENTAH PT UNITEX, TBK
}

\author{
Prima Fithri*), Chairunnisa \\ Jurusan Teknik Industri, Fakultas Teknik, Universitas Andalas \\ Kampus Limau Manis, Padang-Sumatera Barat, Kode Pos 25163 \\ (Received: January 8, 2018/Accepted: February 18, 2019)
}

\begin{abstract}
Abstrak
PT Unitex merupakan perusahaan manufaktur yang bergerak di industri tekstil yang mengolah kapas menjadi kain jadi. Departemen tenun adalah salah satu departemen di PT Unitex, yang memproses benang menjadi kain mentah. Seringnya terjadi permasalahan terhadap pengendalian mutu yang tidak mencapai target di Departemen Tenun, menyebabkan peningkatan waktu pemrosesan produk untuk memperbaiki produk yang cacat juga akan berdampak pada jumlah produksi. Untuk itu penelitian dilakukan dengan mengidentifikasi dan menganalisis proses pengendalian mutu untuk mengetahui faktor utama penyebab terjadinya produk cacat sehingga didapatkan ususlan untuk mengurangi jumlah produk cacat pada hasil produksi. Metode yang digunakan dalam penelitian ini adalah Metode Six Sigma, dengan langkah-langkah Define, Measure, Analyze, Improve, and Control (DMAIC). Berdasarkan hasil perhitungan, didapatkan nilai Defect per Million Opportunity yang diperoleh adalah sebesar 181.67 dan nilai Sigma sebesar 5.07. Dengan nilai sigma sebesar 5.07 berarti Departmen Tenun telah mencapai tingkat industri rata-rata USA. Tapi masih ada cacat yang terjadi dari satu juta peluang. Untuk memaksimalkan kontrol kualitas, rekomendasinya adalah untuk memperkuat pengawasan kepada operator, memprioritaskan pemeriksaan mesin, dan menekankan ketersediaan suku cadang mesin, terutama yang rentan terhadap kerusakan.
\end{abstract}

Kata kunci: DPMO; Six Sigma; Pengendalian Mutu; Produksi; Departemen Tenun

\begin{abstract}
PT Unitex is a manufacturing company engaged in the textile industry. Processing carried out at PT Unitex is processing cotton into finished cloth. The Weaving Department is one of the departments at PT Unitex, which processes yarn into raw fabrics. The most frequent and most noticed problem in the Weaving Department is the quality control problem that often does not reach the target. In addition, this also causes an increase in product processing time to repair defective products which will also have an impact on the amount of production. For this reason, this research is carried out by identifying and analyzing the quality control process to determine the main factors causing the occurrence of defective products so that will reduce the number of defective products in the production. The method used in this study is the Six Sigma Method, with steps Define, Measure, Analyze, Improve, and Control (DMAIC). As soon as the calculation is done, the Defect per Million Opportunity (DPMO) value obtained is 181.67 and the Sigma value is 5.07. With a sigma value of 5.07, Weaving Department has reached the average industry level of the USA. But there are still defects that occur from one million opportunities. To maximize quality control, the recommendations are to strengthen supervision of operators, prioritize inspection of machinery, and emphasize the availability of machine parts, especially those that are vulnerable to damage.
\end{abstract}

Keywords: DPMO; Six Sigma; Production; Quality Control; Weaving Department

\section{Pendahuluan}

\footnotetext{
${ }^{*}$ Penulis Korespondensi.

E-mail: pfithri28@gmail.com
}

PT UNITEX merupakan salah satu perusahaan tekstil yang ada di Indonesia. Sebagai salah satu perusahaan tekstil di Indonesia, persaingan pasar dalam dan luar negeri adalah salah satu tantangan yang tidak dapat dihindari. Persaingan ketat antar perusahaan penghasil tekstil ini menuntut perusahaan untuk memiliki 
kelebihan yang dapat mendatangkan keuntungan terhadap perusahaan itu sendiri. Salah satu cara untuk memenangkan persaingan ini adalah menarik konsumen dengan menghasilkan produk yang sesuai dengan kebutuhan dan keinginan konsumen [1]-[3]. Perusahaan harus pandai melihat kebutuhan dan keinginan konsumen sehingga produk yang dihasilkan akan dapat bersaing di pasaran [4]. Hal lain yang harus dilakukan adalah dengan menawarkan produk dengan kualitas terbaik dan mampu mempertahankan serta senantiasa meningkatkan kualitas dari produk yang dihasilkan [5].

Suatu produk dikatakan berkualitas apabila produk tersebut memenuhi kriteria yang telah ditetapkan perusahaan dan sesuai dengan keinginan konsumen. Pengecekan kualitas produk dilakukan pada bagian kontrol kualitas (quality control) oleh masing-masing industri. Suatu proses produksi tidak selalu dapat menghasilkan produk dengan kualitas bagus. Adakalanya produk yang dihasilkan tidak sesuai dengan ketetapan perusahaan yang disebut dengan produk cacat. Hal ini akan menyebabkan kerugian bagi perusahaan karena produk cacat ini tidak dapat dilepas ke pasaran. Salah satu perusahaan yang memiliki permasalahan dengan pengendalian kualitas adalah PT Unitex.

PT Unitex merupakan perusahaan manufaktur yang bergerak di bidang industri tekstil. Pengolahan yang dilakukan pada PT Unitex yaitu pengolahan kapas menjadi kain jadi. Kapasitas produksi yang terdapat pada perusahaan ini cukup besar. Pihak perusahaan memiliki suatu bagian yang bekerja untuk melakukan pengontrolan kualitas terhadap kain mentah yang dihasilkan. Kain yang tidak memenuhi kualitas disebut dengan produk cacat. Penyebab dominan produk cacat disebabkan oleh manusia, mesin, bahan baku, dan desain. Oleh karena itu hal ini menjadi salah satu permasalahan yang harus diketahui penyebab dan dicari solusinya agar perusahaan tidak mengalami banyak kerugian. Pada PT Unitex terdapat 4 bagian pabrik yaitu Spinning, Weaving, Dyeing, dan Finishing, namun penelitian ini akan dikhususkan kepada Bagian Weaving.

Departemen Weaving yaitu bagian dari pengolahan kain pada PT Unitex yang mengolah benang menjadi kain mentah. Permasalahan yang paling sering dan sangat diperhatikan pada Departemen Weaving adalah masalah pengendalian kualitas yang sering kali tidak mencapai target.

Berdasarkan data yang diperoleh, dalam 24 periode terdapat 9 periode yang mencapai target. Hal ini menyebabkan penurunan dari jumlah produksi di setiap harinya. Selain itu juga menyebabkan bertambahnya waktu pengerjaan produk yaitu untuk memperbaiki produk yang cacat, yang juga akan berdampak pada jumlah produksi. Sehingga permasalahan kualitas ini juga menjadi salah satu penyebab tidak tercapainya target produksi yang telah ditetapkan oleh perusahaan. Permasalahan tersebut dapat diselesaikan dengan metode
Six Sigma. Telah banyak penelitian yang menggunakan metode Six Sigma untuk menyelesaikan masalah kualitas [6]-[9].

\section{Bahan dan Metode}

Sigma merupakan sebuah abjad Yunani yang menunjukkan standar deviasi dari suatu proses. Standar deviasi mengukur variasi atau jumlah persebaran suatu rata-rata proses. Nilai sigma dapat diartikan seberapa sering cacat yang mungkin terjadi. Jika semakin tinggi tingkat sigma maka semakin kecil toleransi yang diberikan pada kecacatan sehingga semakin tinggi kapabilitas proses, dan hal itu dikatakan semakin baik.

Six sigma menganjurkan bahwa terdapat hubungan yang kuat antara cacat produk dan produk yang dihasilkan, reliability, costs, cycle time, inventory, schedule, dan lainnya. Bila jumlah cacat yang meningkat, maka jumlah sigma akan menurun. Dengan kata lain, dengan nilai sigma yang lebih besar maka kualitas produk akan lebih baik.

Six sigma merupakan suatu visi peningkatan kualitas menuju target 3.4 kegagalan per sejuta kesempatan (DPMO) untuk setiap transaksi produk (barang dan/atau jasa), upaya giat menuju kesempurnaan zero defect / kegagalan nol. Jadi Six sigma adalah sebuah sistem yang komprehensif dan fleksibel untuk mencapai, mempertahankan, dan memaksimalkan sukses bisnis. Six sigma secara unik dikendalikan oleh pemahaman yang kuat terhadap kebutuhan pelanggan, pemakaian yang disiplin terhadap fakta, data, analisis statistik, dan perhatian yang cermat untuk mengelola, memperbaiki, dan menanamkan kembali proses bisnis.

Six sigma menggunakan alat statistik untuk mengidentifikasi beberapa faktor permasalahan yang terjadi, Siklus DMAIC merupakan proses kunci untuk peningkatan secara kontinyu menuju target Six sigma. DMAIC dilakukan secara sistematik berdasarkan ilmu pengetahuan dan fakta (systematic, scientific, and fact based). Berikut ini adalah tahapan dalam siklus DMAIC dan langkah-langkah yang harus dilaksanakan pada setiap tahap.

\section{Define (D)}

Tahap Define merupakan langkah operasional pertama dalam program peningkatan kualitas Six sigma. Dalam tahap define dilakukan identifikasi proyek yang potensial, mendefinisikan peran orang-orang yang terlibat dalam proyek Six sigma, mengidentifikasi karakteristik kualitas kunci (CTQ) yang berhubungan langsung dengan kebutuhan spesifik dari pelanggan dan menentukan tujuan.

Pada tahapan ini ditentukan proporsi defect yang menjadi penyebab paling signifikan terhadap adanya kerusakan yang merupakan sumber kegagalan produksi. Cara yang ditempuh adalah (Muhaemin, 2012): 
a. Mendefinisikan masalah standar kualitas dalam menghasilkan produk yang telah ditentukan perusahaan.

b. Mendefinisikan rencana tindakan yang harus dilakukan berdasarkan hasil observasi dan analisis penelitian.

c. Menetapkan sasaran dan tujuan peningkatan kualitas Six sigma berdasarkan hasil observasi.

\section{Measure (M)}

Measure merupakan langkah operasional kedua dalam program peningkatan kualitas Six sigma, terdapat beberapa hal pokok yang harus dilakukan yaitu:

a. Melakukan dan mengembangkan rencana pengumpulan data yang dapat dilakukan pada tingkat proses dan output.

b. Mengukur kinerja sekarang (current performance) untuk ditetapkan sebagai baseline kinerja pada awal proyek six sigma.

\section{Analyze (A)}

Merupakan langkah operasional ketiga dalam program peningkatan kualitas Six sigma. Sebenarnya target dari program Six sigma adalah membawa proses industri pada kondisi yang memiliki stabilitas (stability) dan kemampuan (capability), sehingga mencapai tingkat kegagalan nol (zero defect oriented).

\section{Improve ( I )}

Apabila penyebab permasalahan kualitas teridentifikasi, maka perlu dilakukan penentapan rencana tindakan (action plan) untuk melaksanakan peningkatan kualitas Six sigma, yaitu dengan tools: Failure Mode and Effect Analysis (FMEA) yang mendiskripsikan tentang alokasi sumber-sumber daya serta prioritas dan atau alternatif yang dilakukan dalam implementasi dari rencana itu. FMEA adalah sekumpulan petunjuk untuk mengidentifikasikan dan mendahulukan masalahmasalah potensial kegagalan. Berdasarkan aktivitas tim pada FMEA maka seorang manajer, tim perbaikan atau penanggung jawab proses dapat memfokuskan energi dan sumber daya pada pencegahan, monitoring, dan rencanarencana tanggapan yang paling mungkin untuk memberikan hasil.

\section{Control ( C )}

Merupakan tahap operasional terakhir dalam proyek peningkatan kualitas Six sigma. Pada tahap ini prosedur-prosedur serta hasil-hasil peningkatan kualitas didokumentasikan untuk dijadikan pedoman kerja standart guna mencegah masalah yang sama atau praktekpraktek lama terulang kembali, kemudian kepemilikan atau tanggung jawab ditransfer dari tim Six sigma kepada penanggung jawab proses, dan ini berarti proyek six sigma berakhir pada tahap ini.
Penyelesaian masalah dilakukan menggunakan Metode Six Sigma yaitu DMAIC, namun pada penelitian ini tidak dilakukan proses Control.

\section{Hasil dan Pembahasan}

Penyelesaian permasalahan kualitas ini dengan metode six sigma karena metode six sigma merupakan salah satu metode pengendalian kualitas yang dapat menentukan penyebab dari masalah kualitas yang terjadi dan dapat memberikan solusi perbaikan.

\section{Pengumpulan Data}

Data yang diperlukan dalam melakukan pembuatan laporan ini adalah data cacat yang terdiri dari Grade A dan Grade C, data produksi dan target produksi. Data yang dikumpulkan yaitu data selama dua tahun terakhir yaitu mulai dari bulan Januari 2015 hingga Desember 2016. Data yang dikumpulkan dapat dilihat pada Tabel 1.

Tabel 1. Data Cacat, Data Produksi dan Target Produksi

\begin{tabular}{clcccc}
\hline No & Periode & $\begin{array}{c}\text { Grade } \\
\text { "A" }\end{array}$ & $\begin{array}{c}\text { Grade } \\
\text { "C" }\end{array}$ & Produksi & Target \\
\hline 1 & JAN & 5965.00 & 689.00 & 807782.40 & 875010.85 \\
\hline 2 & FEB & 5410.25 & 623.00 & 685821.60 & 713998.48 \\
\hline 3 & MAR & 5676.50 & 461.00 & 689682.00 & 673200.00 \\
\hline 4 & APR & 5871.00 & 348.00 & 650422.80 & 699000.00 \\
\hline 5 & MAY & 5757.25 & 410.50 & 652970.40 & 688800.00 \\
\hline 6 & JUN & 5733.00 & 304.50 & 599010.00 & 640000.00 \\
\hline 7 & JUL & 3636.25 & 289.25 & 429855.60 & 450010.02 \\
\hline 8 & AUG & 4239.00 & 379.25 & 452857.20 & 437000.00 \\
\hline 9 & SEP & 5524.50 & 422.00 & 682689.60 & 757000.00 \\
\hline 10 & OCT & 5634.25 & 340.50 & 694980.00 & 658000.00 \\
\hline 11 & NOV & 5744.75 & 317.50 & 711886.80 & 658000.00 \\
\hline 12 & DEC & 5374.75 & 372.00 & 650422.80 & 699000.00 \\
\hline 13 & JAN & 4640.25 & 452.75 & 574258.80 & 620000.00 \\
\hline 14 & FEB & 6099.00 & 368.75 & 739848.00 & 728000.00 \\
\hline 15 & MAR & 6528.75 & 409.00 & 740673.60 & 738010.80 \\
\hline 16 & APR & 6177.00 & 416.75 & 730833.60 & 738000.00 \\
\hline 17 & MAY & 5753.75 & 491.25 & 714409.20 & 738000.00 \\
\hline 18 & JUN & 7178.50 & 302.25 & 756298.80 & 738000.00 \\
\hline 19 & JUL & 4020.71 & 336.00 & 520698.00 & 541200.00 \\
\hline 20 & AUG & 5060.05 & 303.25 & 643828.80 & 640000.00 \\
\hline 21 & SEP & 5167.15 & 300.00 & 658828.80 & 720004.27 \\
\hline 22 & OCT & 5642.98 & 355.75 & 713480.40 & 700000.00 \\
\hline 23 & NOV & 5414.64 & 263.00 & 688420.80 & 699991.35 \\
\hline 24 & DEC & 5367.97 & 296.50 & 662288.40 & 676658.31 \\
\hline JUMLAH & 131617.25 & 9251.75 & 15852248.40 & 16226884.08 \\
\hline & & & & & \\
\hline
\end{tabular}

\section{Pengendalian Mutu}

Pengendalian mutu pada PT Unitex berorientasi pada proses. Proses peroduksi kain graige melalui tujuh proses produksi yaitu RT Winder, Kowari, Warper, Sizing, Reaching, Shokki, Shiage. Proses tenun (shokki) merupakan proses pertenunan kain greige dengan menggunakan mesin tipe AJL (Air Jet Lum), ISL (Ishikawa Sailor Loom), dan Dobby. Pada proses tenun 
(shokki) merupakan proses yang mengakibatkan banyak cacat kain yang terjadi diakibatkan oleh mesin yang sering mengalami masalah.

\section{a. Kebijakan Mutu}

i. Menghasilkan produk yang memiliki kualitas baik. PT Unitex sangat memperhatikan segala hal yang berkaitan dengan mutu kainnya. Dengan cara melihat kualitas dari kapas yang akan diolah menjadi benang dan kualitas benangpun akan diperiksa sebelum menjadi kain, dan kain yang sudah jadi pun diperiksa sebelum dipacking. Karena produk yang dihasilkan nantinya akan diekspor ke negara asing seperti Amerika, Jepang, dan Australia yang sangat mengutamakan kualitas baik.

ii. Mengutamakan keselamatan para pekerja. PT Unitex ingin seluruh karyawan tetap aman dalam lingkungan tempat kerja, untuk itu PT Unitex telah menyediakan alat pelindung diri agar terhindar dari kecelakaan kerja dan kesehatan di tempat kerja.

iii. Meningkatkan efisisensi dan produktifitas. PT Unitex membuat kebijakan ini dengan tujuan agar seluruh produksi yang dilakukan dapat mengefisienkan waktu dan tenaga kerja dengan cara membeli mesin tenun otomatis agar bekerja tepat waktu, dan untuk produktivitas PT Unitex ini memaksimalkan setiap produksinya sehingga dapat mengurangi jumlah kain cacat.

iv. Melakukan perbaikan secara terus-menerus dan konsisten. Kebijakan mutu ini dibuat oleh PT Unitex untuk memantau setiap bulannya apa saja yang masih harus dibenahi dan apa saja yang sudah mulai cukup baik. Untuk itu diadakan audit internal oleh pihak quality control PT Unitex.

PT Unitex sudah menerapkan dan melakukan beberapa pembenahan untuk standar mutu atau ISO dari tahun 2001. ISO yang diterapkan PT Unitex yaitu ISO 9001:2008. PT Unitex sangat konsisten dalam menjalankan kebijakan mutu yang telah ditetapkan sampai sekarang, salah satu langkah untuk memperbaiki atau meningkatkan standar mutu dengan diadakan pelatihan untuk para karyawan agar dapat lebih sadar akan pentingnya pengendalian mutu dalam suatu perusahaan. ISO 9001 merupakan sistem yang menetapkan standar-standar manajemen kualitas yang harus ditetapkan untuk mencapai kepuasan konsumen. ISO 9001 ini berbentuk fisik berupa dokumen yang berisi seluruh kejadian awal yang menekankan bahwa mutu tercatat dengan baik.

\section{b. Jenis-Jenis Cacat}

i. Grade A adalah jenis cacat yang sangat kecil. Cacat ini diakibatkan karena adanya kotoran pada benang, atau belang pada warna benang hanya 0 30 point per $100 \mathrm{~m}^{2}$ untuk ekspor, sedangkan untuk lokal 0-36 point per $\mathrm{m}^{2}$. Contohnya pemeriksaan kain yang dilakukan pada mesin kentan shiage, operator menemukan adanya cacat kain yang diakibatkan oleh kotoran yang menempel di benang (nep) hanya 0.75 dari keseluruhan panjang kain.

ii. Grade $\mathrm{C}$ adalah jenis cacat yang diakibatkan kesalahan dalam setting mesin yang tidak sesuai standar ataupun akibat kesalahan cara kerja operator yang tidak sesuai dengan standar kerja, meskipun kain ini cacat dan masuk Grade $\mathrm{C}$, kain ini masih dapat diperbaiki cacatnya oleh operator.

iii. Lain-lain adalah jenis cacat yang diakibatkan dari noda, dan potongan kain yang tidak sesuai.

Kategori grade jenis cacat kain greige sudah diketahui yaitu adanya grade $\mathrm{A}$ dan $\mathrm{C}$ serta jenis kain cacat yang mudah diatasi seperti noda dan pemotongan kain yang tidak sesuai dengan orderan.

\section{Six Sigma}

Tahapan penyelesaian masalah pengendalian kualitas menggunakan metode six sigma yaitu sebagai berikut.

\section{Define}

Pada tahap ini akan dilakukan identifikasi masalah yang akan diselesaikan. Permasalahan yang diuraikan dalam tahap ini menentukan Critical to Quality (CTQ). CTQ merupakan suatu cara pengukuran produk atau proses yang mana standar kinerja atau batas spesifikasinya harus sesuai dengan kepuasan pelanggan. Karena suksesnya suatu perusahaan itu sangat bergantung dengan kepuasan pelanggan terhadap produk yang dihasilkan.

Kriteria yang ditentukan dalam CTQ untuk menjaga kualitas produknya yaitu:
a. Anyaman
b. Benang
c. Kebersihan
d. Keadaan kain
e. Design

\section{Measure}

Tahapan kedua dalam metode six sigma yaitu measure. Pada tahap ini yang dilakukan yaitu sebagai berikut:

a. Peta Kendali P Produk Cacat

Pembuatan peta kendali bertujuan untuk melihat apakah data yang digunakan dalam melakukan perhitungan six sigma nantinya berada dalam batas control atau tidak. Jika terdapat data yang keluar dari batas control dan diketahui penyebabnya, buang data dan lakukan perhitungan ulang untuk mendapatkan CL, UCL, dan LCL sampai revisi data berada dalam batas kendali. Langkah pembuatan peta kendali P yaitu: 
i. Pemeriksaan terhadap $\mathrm{n}$ barang yang cacat Dari data hasil produksi kain mentah PT Unitex Bagian weaving tahun 2015 - 2016 ditentukan jumlah produk yang cacat. Produk yang cacat tersebut disebut non conforming yang kemudian terbagi 2 yaitu Grade A dan Grade C. Grade A merupakan produk yang memiliki poin cacat yang sedikit dan masih bisa ditanggulangi sehingga dan masih bisa digunakan pada proses selanjutnya namun cukup memakan waktu. Grade C merupakan produk poin cacat yang besar dan sulit untuk ditanggulangi sehingga sangat kecil kemungkinan untuk digunakan pada proses selanjutnya.

ii. Menentukan jumlah cacat produk

$$
\begin{aligned}
\bar{P} & =\frac{\text { Jumlah Produk Ditolak }}{\text { Jumlah Produk Diperiksa }} \\
\bar{P} & =\frac{689}{807782} \\
& =0,00085
\end{aligned}
$$

iii. Menentukan rata - rata cacat dari seluruh slab baja yang diperiksa

$$
\begin{aligned}
\bar{P} & =\frac{\text { Total Jumlah Produk Ditolak }}{\text { Total Jumlah Produk Diperiksa }} \\
\bar{P} & =\frac{15852248,4}{16226884,08} \\
& =0,00058
\end{aligned}
$$

iv. Menentukan standar deviasi cacat slab baja dengan rumus:

1. Garis sentral Central Limit (CL)

$$
\begin{aligned}
(\mathrm{CL}) & =\bar{P} \\
& =0,00058
\end{aligned}
$$

2. Batas kendali atas (Upper Control Limit)

$$
\begin{aligned}
\mathrm{UCL} & =p+3 \frac{\sqrt{\bar{P}}(1-\bar{P})}{\mathrm{n}} \\
& =0,00058+3 \\
& \frac{\sqrt{0,00058}(1-0,00058)}{807782,4} \\
& =0,00095
\end{aligned}
$$

3. Batas kendali bawah (Lower Control Limit)

$$
\begin{aligned}
\mathrm{LCL} & =p-3 \frac{\sqrt{\bar{P}}(1-\bar{P})}{\mathrm{n}} \\
& =0,00058-3 \\
& \frac{\sqrt{0,00058}(1-0,00058)}{807782,4}
\end{aligned}
$$

$$
=0,00076
$$

Rekapitulasi dari nilai P, CL, UCL dan CL yang telah dihitung sebelumnya dapat dilihat pada Tabel 2.

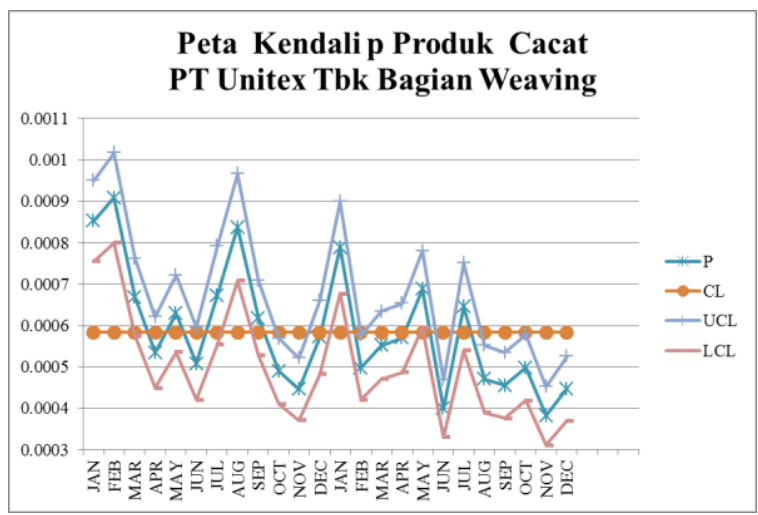

Gambar 1. Peta Kendali P Produk Cacat

Dari Tabel 2 dapat dilihat bahwa tidak ada data yang berada di luar batas kontrol. Oleh karena itu tidak perlu dilakukan revisi untuk data ini, dan data dapat digunakan untuk pengolahan selanjutnya.

\section{Analyze}

Langkah selanjutnya yang dilakukan yaitu analyz, dilakukan dengan menggunakan diagram sebab akibat dan FMEA sehingga dapat diketahui faktor-faktor penyebab kerusakan dan cacat produk.

a. Diagram Sebab Akibat

Diagram Sebab Akibat merupakan diagram yang dibuat untuk mencari akar permasalahan dari cacat hasil produksi kain mentah PT Unitex Bagian Weaving. Diagram ini dapat memberikan informasi tentang penyebab terjadinya cacat produk karena kegagalan dalam mencapai standar CTQ yang telah ada. Diagram Sebab Akibat dari produk cacat dapat dilihat pada Gambar 2.

b. FMEA

Setelah diperoleh penyebab-penyebab dari terjadinya produk cacat, selanjutnya dilakukan analisa untuk mengetahui penyebab yang paling berisiko dengan menggunakan FMEA. Tabel FMEA hasil diskusi dengan pihak perusahaan dapat dilihat pada Tabel 3. 
Tabel 2. Peta Kendali P Produk Cacat

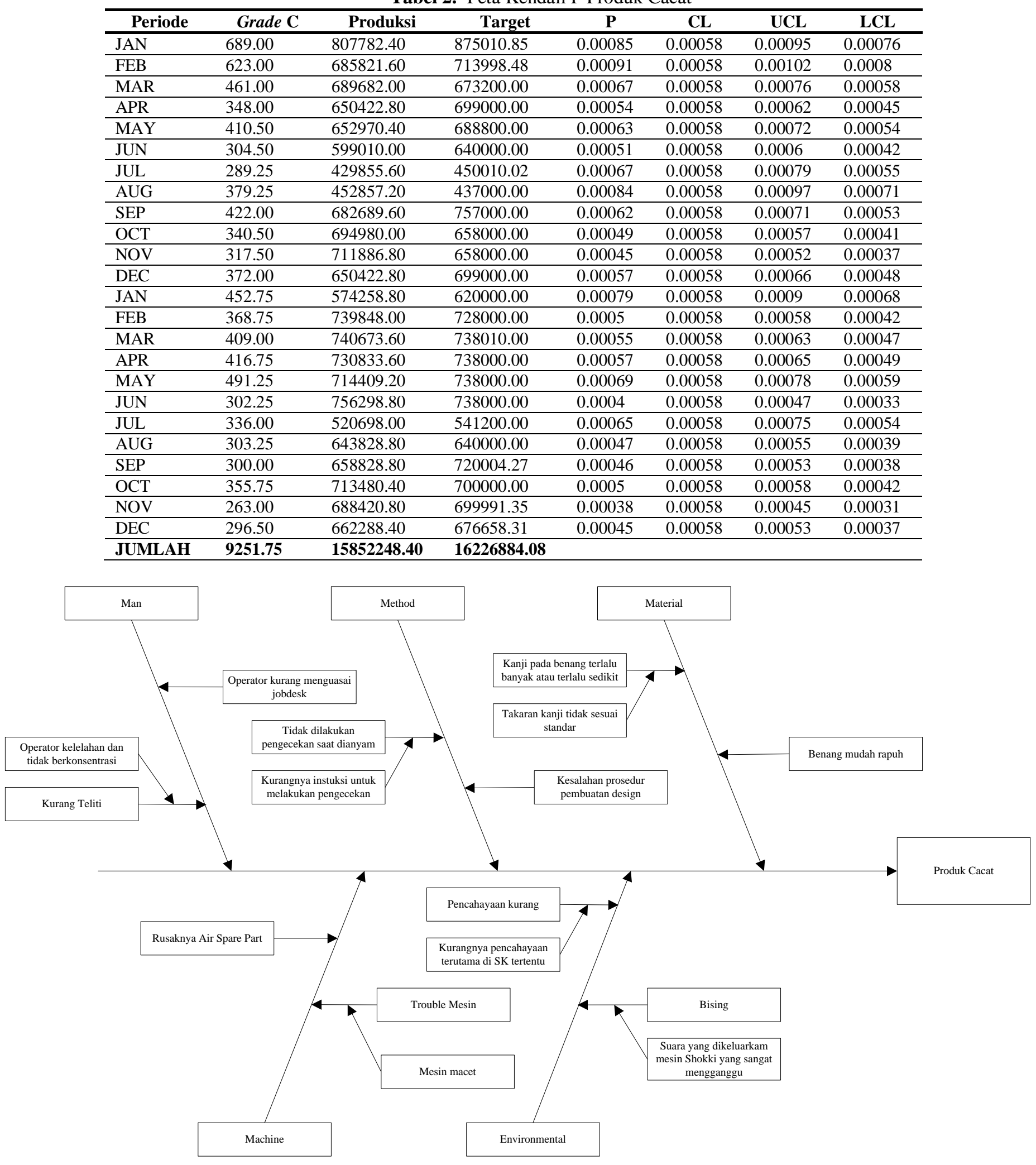

Gambar 2. Diagram Sebab Akibat 
Tabel 3. FMEA

\begin{tabular}{|c|c|c|c|c|c|c|c|c|c|}
\hline No & $\begin{array}{c}\text { Proses } \\
\text { Permesinan }\end{array}$ & $\begin{array}{c}\text { Potential } \\
\text { Failure } \\
\text { Mode }\end{array}$ & $\begin{array}{c}\text { Potential } \\
\text { Effect of } \\
\text { Mode }\end{array}$ & Severity & $\begin{array}{c}\text { Potential Cause of } \\
\text { Failure }\end{array}$ & Occurance & Current Control & Detection & RPN \\
\hline \multirow[b]{2}{*}{1} & \multirow{2}{*}{$\begin{array}{l}\text { Pemilihan } \\
\text { dan } \\
\text { penyimpanan } \\
\text { bahan baku } \\
\text { RT Winder }\end{array}$} & \multirow{2}{*}{$\begin{array}{l}\text { Bahan baku } \\
\text { tidak sesuai } \\
\text { standar }\end{array}$} & \multirow{2}{*}{$\begin{array}{l}\text { Benang yang } \\
\text { dihasilkan } \\
\text { rapuh dan } \\
\text { tidak sesuai } \\
\text { standar }\end{array}$} & 8 & Operator kurang teliti & 4 & $\begin{array}{l}\text { Pengawasan lebih } \\
\text { diperketat }\end{array}$ & 1 & 32 \\
\hline & & & & 8 & $\begin{array}{l}\text { Penggunaan sisa hasil } \\
\text { produksi sebelumnya }\end{array}$ & 2 & $\begin{array}{l}\text { Pengecekan bahan } \\
\text { baku sebelum di } \\
\text { penyimpanan }\end{array}$ & 2 & 32 \\
\hline \multirow{2}{*}{2} & \multirow{2}{*}{ RT Winder } & $\begin{array}{l}\text { Benang } \\
\text { pada paper } \\
\text { cores putus }\end{array}$ & \multirow{2}{*}{$\begin{array}{l}\text { Benang pada } \\
\text { paper cones } \\
\text { tidak dapat } \\
\text { diolah pada } \\
\text { proses } \\
\text { selanjutnya }\end{array}$} & 8 & $\begin{array}{l}\text { Kualitas benang tidak } \\
\text { sesuai standar }\end{array}$ & 2 & $\begin{array}{l}\text { Pengecekan bahan } \\
\text { baku sebelum } \\
\text { digunakan }\end{array}$ & 3 & 48 \\
\hline & & $\begin{array}{l}\text { Benang } \\
\text { pada paper } \\
\text { cores kusut }\end{array}$ & & 8 & $\begin{array}{l}\text { Kurangnya } \\
\text { pengawasan dari } \\
\text { operator }\end{array}$ & 3 & $\begin{array}{l}\text { Pengawasan lebih } \\
\text { diperketat }\end{array}$ & 4 & 96 \\
\hline \multirow[b]{2}{*}{3} & \multirow[b]{2}{*}{ Kowari } & \multirow{2}{*}{$\begin{array}{l}\text { Penyortiran } \\
\text { benang } \\
\text { tidak sesuai } \\
\text { dengan } \\
\text { orderan } \\
\text { buyer }\end{array}$} & \multirow{2}{*}{$\begin{array}{l}\text { Kesalahan } \\
\text { desain yang } \\
\text { tidak sesuai } \\
\text { dengan } \\
\text { orderan } \\
\text { buyer }\end{array}$} & 6 & $\begin{array}{l}\text { Operator kurang teliti } \\
\text { dalam melakukan } \\
\text { penyortiran }\end{array}$ & 3 & $\begin{array}{l}\text { Pengawasan lebih } \\
\text { diperketat }\end{array}$ & 1 & 18 \\
\hline & & & & 6 & $\begin{array}{l}\text { Operator tidak } \\
\text { melakukan pe- } \\
\text { ngecekan ulang } \\
\text { terhadap desain yang } \\
\text { dibuat }\end{array}$ & 3 & $\begin{array}{l}\text { Pengawasan lebih } \\
\text { diperketat }\end{array}$ & 3 & 54 \\
\hline 4 & Warper & $\begin{array}{l}\text { Benang } \\
\text { yang } \\
\text { digulung } \\
\text { pada beam } \\
\text { putus }\end{array}$ & $\begin{array}{l}\text { Mempersulit } \\
\text { dan menam- } \\
\text { bah waktu } \\
\text { pengerjaan } \\
\text { pada proses } \\
\text { selanjutnya }\end{array}$ & 8 & $\begin{array}{l}\text { Kurangnya } \\
\text { pengawasan dari } \\
\text { operator }\end{array}$ & 3 & $\begin{array}{l}\text { Pengawasan lebih } \\
\text { diperketat }\end{array}$ & 2 & 4 \\
\hline \multirow[t]{2}{*}{5} & \multirow[t]{2}{*}{ Sizing } & $\begin{array}{l}\text { Pemberian } \\
\text { kanji pada } \\
\text { benang } \\
\text { terlalu } \\
\text { banyak }\end{array}$ & $\begin{array}{l}\text { Bulu benang } \\
\text { terbuka } \\
\text { sehingga } \\
\text { memperbesar } \\
\text { cacat yang } \\
\text { ditimbulkan } \\
\text { pada proses } \\
\text { selanjutnya }\end{array}$ & 7 & $\begin{array}{l}\text { Bahan baku kanji } \\
\text { tidak sesuai standar }\end{array}$ & 4 & $\begin{array}{l}\text { Pengecekan } \\
\text { berkala terhadap } \\
\text { bahan baku dari } \\
\text { supplier }\end{array}$ & 3 & 84 \\
\hline & & $\begin{array}{l}\text { Pemberian } \\
\text { kanji pada } \\
\text { benang } \\
\text { terlalu } \\
\text { sedikit }\end{array}$ & $\begin{array}{l}\text { Kanji } \\
\text { menumpuk } \\
\text { pada benang } \\
\text { memudahkan } \\
\text { kotoran } \\
\text { menempel } \\
\end{array}$ & 7 & $\begin{array}{l}\text { Bahan baku kanji } \\
\text { tidak sesuai standar }\end{array}$ & 4 & $\begin{array}{l}\text { Pengecekan } \\
\text { berkala terhadap } \\
\text { bahan baku dari } \\
\text { supplier }\end{array}$ & 3 & 84 \\
\hline 6 & Reaching & $\begin{array}{l}\text { Susunan } \\
\text { benang } \\
\text { tidak sesuai } \\
\text { orderan } \\
\text { buyer }\end{array}$ & $\begin{array}{l}\text { Kesalahan } \\
\text { desain yang } \\
\text { tidak sesuai } \\
\text { orderan } \\
\text { buyer }\end{array}$ & 6 & $\begin{array}{l}\text { Operator kurang teliti } \\
\text { dan menguasai desain } \\
\text { yang diorder buyer }\end{array}$ & 5 & $\begin{array}{l}\text { Ketelitian } \\
\text { operator dalam } \\
\text { melakukan } \\
\text { pekerjaan lebih } \\
\text { diperhatikan } \\
\end{array}$ & 3 & 90 \\
\hline \multirow{3}{*}{7} & \multirow{3}{*}{ Shokki } & $\begin{array}{l}\text { Design } \\
\text { tidak sesuai } \\
\text { permintaan } \\
\text { buyer }\end{array}$ & \multirow{3}{*}{$\begin{array}{l}\text { Anyaman } \\
\text { rapat, } \\
\text { renggang, } \\
\text { double, } \\
\text { kusut, putus, } \\
\text { dll }\end{array}$} & 6 & $\begin{array}{l}\text { Kurangnya } \\
\text { pengawasan dari } \\
\text { operator }\end{array}$ & 4 & $\begin{array}{l}\text { Ketelitian } \\
\text { operator dalam } \\
\text { melakukan } \\
\text { pekerjaan lebih } \\
\text { diperhatikan } \\
\end{array}$ & 3 & 72 \\
\hline & & $\begin{array}{l}\text { Mesin } \\
\text { rusak atau } \\
\text { mati saat } \\
\text { produksi }\end{array}$ & & 8 & $\begin{array}{l}\text { Terdapat kesalahan } \\
\text { saat melakukan setup } \\
\text { mesin }\end{array}$ & 5 & $\begin{array}{l}\text { Pengerjaan dan } \\
\text { pengawasan lebih } \\
\text { teliti dan ketat }\end{array}$ & 6 & 240 \\
\hline & & $\begin{array}{l}\text { Cacat pada } \\
\text { hasil akhir } \\
\text { kain }\end{array}$ & & 7 & $\begin{array}{l}\text { Bahan baku tidak } \\
\text { sesuai standar }\end{array}$ & 3 & $\begin{array}{l}\text { Melakukan } \\
\text { pengecekan bahan } \\
\text { baku sebelum } \\
\text { digunakan }\end{array}$ & 4 & 84 \\
\hline
\end{tabular}


Berdasarkan tabel di atas, dapat diketahui bahwa risiko tertinggi menyebabkan cacat produk dengan nilai 240 terdapat pada proses Shokki. Cacat produk terjadi karena mesin yang mati atau rusak saat melakukan proses produksi. Penyebabnya adalah karena terdapat kesalahan saat melakukan setup mesin, tensi mesin tidak seimbang dan juga hal hal lain terkait penjagaan dan perawatan mesin. Dampak dari penyebab ini adalah kain yang dihasilkan tidak memenuhi standar kualitas yang telah ditetapkan perusahaan dikarenakan cacat yang terjadi akibat kesalahan pada mesin.

\section{Improve}

Tahapan ini bertujuan untuk melakukan peningkatan agar penyebab-penyebab yang berpotensi mengakibatkan produk cacat berkurang. Tahapan ini dilakukan dengan menggunakan Five M-Checklist.

\section{Five-M Checklist}

Penggunaan Five M-Checklist didasarkan kepada diagram sebab-akibat sebelumnya. Penyelesaian Five M-Checklist dapat dilihat pada Tabel 4.

Tabel 4. Five-M Checklist

\begin{tabular}{|c|c|c|c|}
\hline No & Faktor & Masalah & $\begin{array}{r}\text { Pemecahan Masalah } \\
\end{array}$ \\
\hline \multirow{3}{*}{1} & \multirow{3}{*}{ Manusia } & $\begin{array}{l}\text { Operator kurang teliti dan } \\
\text { ceroboh }\end{array}$ & $\begin{array}{l}\text { Menegur dan menyadarkan pekerja akan pentingnya ketelitian } \\
\text { saat melakukan tugasnya, karena akan sangat berdampak pada } \\
\text { hasil produksi nantinya }\end{array}$ \\
\hline & & Kurang sadarkan kualitas & $\begin{array}{l}\text { Tingkatkan kepedulian pekerja akan kualitas melalui pertemuan } \\
\text { maupun teguran langsung, karena prinsip yang bagus itu adalah } \\
\text { menerima produk yang baik dan memberikan produk yang baik } \\
\text { pula. Hal ini harus lebih diterapkan pada pekerja yang } \\
\text { mengkontrol mesin di setiap stasiun kerja. }\end{array}$ \\
\hline & & $\begin{array}{l}\text { Karyawan baru yang belum } \\
\text { terlatih }\end{array}$ & $\begin{array}{l}\text { Karyawan baru harus diberi pelatihan maupun pengetahuan } \\
\text { tentang pekerjaannya sebelum terjun langsung bekerja dan } \\
\text { belajar bersama seniornya }\end{array}$ \\
\hline \multirow[t]{2}{*}{2} & \multirow[t]{2}{*}{ Mesin } & $\begin{array}{l}\text { Terdapat bagian mesin yang } \\
\text { berpotensi rusak }\end{array}$ & $\begin{array}{l}\text { Lakukan pengawasan yang ekstra terhadap bagian mesin yang } \\
\text { sering rusak. Selalu sediakan bahan cadangan terhadap bagian } \\
\text { mesin tersebut }\end{array}$ \\
\hline & & Setting mesin kurang tepat & $\begin{array}{l}\text { Tingkatkan ketelitian pekerja. Ganti peralatan yang sudah tidak } \\
\text { sesuai standar yang mengakibatkan setingan kurang tepat }\end{array}$ \\
\hline 3 & Material & $\begin{array}{l}\text { Bahan baku tidak sesuai } \\
\text { standar }\end{array}$ & $\begin{array}{l}\text { Tingkatkan standar kualitas bahan baku yang diterima, } \\
\text { tingkatkan ketelitian dan pengawasan pekerja serta tingkatkan } \\
\text { keberanian perkerja untuk menyatakan bahwa bahan baku } \\
\text { ditolak }\end{array}$ \\
\hline \multirow[t]{2}{*}{4} & \multirow[t]{2}{*}{ Metode } & $\begin{array}{l}\text { Kurang pertemuan berupa } \\
\text { pengarahan terhadap sesama } \\
\text { karyawan maupun dengan } \\
\text { atasan }\end{array}$ & $\begin{array}{l}\text { Lakukan briefing setiap hari antara kepala produksi maupun } \\
\text { asistennya bersama pekerja di setiap stasiun kerja sebelum } \\
\text { memulai pekerjaan karena diskusi kecil maupun tukar pikiran } \\
\text { secara langsung akan memberi informasi yang lebih bermanfaat } \\
\text { dibandingkan dengan laporan tertulis yang dikumpulkan setiap } \\
\text { hari. }\end{array}$ \\
\hline & & $\begin{array}{l}\text { Kesalahan prosedur } \\
\text { pembuatan desain }\end{array}$ & $\begin{array}{l}\text { Lakukan arahan oleh atasan kepada operator untuk memahami } \\
\text { terlebih dahulu desain yang akan dibuat sebelum melakukan } \\
\text { produksi. }\end{array}$ \\
\hline \multirow[b]{2}{*}{5} & \multirow[b]{2}{*}{ Lingkungan } & $\begin{array}{l}\text { Lingkungan kerja yang } \\
\text { kurang kondusif (bising, } \\
\text { redup, dan berkabut) }\end{array}$ & $\begin{array}{l}\text { Lengkapi pekerja dengan peralatan seperti masker dan ear plug } \\
\text { saat serta penerangan yang cukup berlangsungnya proses } \\
\text { produksi. }\end{array}$ \\
\hline & & $\begin{array}{l}\text { Letak job description yang } \\
\text { kurang tepat }\end{array}$ & $\begin{array}{l}\text { Ganti lokasi peletakan job description menjadi lebih baik, } \\
\text { contohnya lokasi yang sejajar dengan arah pandangan agar } \\
\text { pekerja yang belum ahli tidak harus mendongak untuk melihat } \\
\text { job description-nya }\end{array}$ \\
\hline
\end{tabular}


Tabel 5. Rekapitulasi perhitungan DPMO dan Six Sigma

\begin{tabular}{cccccccc}
\hline No & Periode & Grade "C" & Total Produksi & CTQ & DPO & DPMO & Six Sigma \\
\hline 1 & JAN & 689.00 & 807782.40 & 5 & 0.00017059 & 170.5905 & 5.08 \\
\hline 2 & FEB & 623.00 & 685821.60 & 5 & 0.00018168 & 181.6799 & 5.07 \\
\hline 3 & MAR & 461.00 & 689682.00 & 5 & 0.000133685 & 133.6848 & 5.15 \\
\hline 4 & APR & 348.00 & 650422.80 & 5 & 0.000107007 & 107.00732 & 5.20 \\
\hline 5 & MAY & 410.50 & 652970.40 & 5 & 0.000125733 & 125.73311 & 5.16 \\
\hline 6 & JUN & 304.50 & 599010.00 & 5 & 0.000101668 & 101.66775 & 5.21 \\
\hline 7 & JUL & 289.25 & 429885.60 & 5 & 0.00013458 & 134.58008 & 5.14 \\
\hline 8 & AUG & 379.25 & 452857.20 & 5 & 0.000167492 & 167.49209 & 5.09 \\
\hline 9 & SEP & 422.00 & 682689.60 & 5 & 0.000123629 & 123.62866 & 5.17 \\
\hline 10 & OCT & 340.50 & 694980.00 & 5 & $9.79884 \mathrm{E}-05$ & 97.988431 & 5.22 \\
\hline 11 & NOV & 317.50 & 711886.80 & 5 & $8.91996 \mathrm{E}-05$ & 89.199575 & 5.25 \\
\hline 12 & DEC & 372.00 & 650422.80 & 5 & 0.000114387 & 114.38713 & 5.18 \\
\hline 13 & JAN & 452.75 & 574258.80 & 5 & 0.000157682 & 157.68152 & 5.10 \\
\hline 14 & FEB & 368.75 & 739848.00 & 5 & $9.96826 \mathrm{E}-05$ & 99.682638 & 5.22 \\
\hline 15 & MAR & 409.00 & 740673.60 & 5 & 0.00011044 & 110.44001 & 5.19 \\
\hline 16 & APR & 416.75 & 730833.60 & 5 & 0.000114048 & 114.04785 & 5.19 \\
\hline 17 & MAY & 491.25 & 714409.20 & 5 & 0.000137526 & 137.52622 & 5.14 \\
\hline 18 & JUN & 302.25 & 756298.80 & 5 & $7.99287 \mathrm{E}-05$ & 79.928727 & 5.28 \\
\hline 19 & JUL & 336.00 & 520698.00 & 5 & 0.000129058 & 129.05753 & 5.15 \\
\hline 20 & AUG & 303.25 & 643828.80 & 5 & $9.42021 \mathrm{E}-05$ & 94.202061 & 5.23 \\
\hline 21 & SEP & 300.00 & 658828.80 & 5 & $9.10707 \mathrm{E}-05$ & 91.0707 & 5.24 \\
\hline 22 & OCT & 355.75 & 713480.40 & 5 & $9.97224 \mathrm{E}-05$ & 99.722431 & 5.22 \\
\hline 23 & NOV & 263.00 & 688420.80 & 5 & $7.64068 \mathrm{E}-05$ & 76.406756 & 5.29 \\
\hline 24 & DEC & 296.50 & 662288.40 & 5 & $8.9538 \mathrm{E}-05$ & 89.538032 & 5.25 \\
\hline & & & & & & &
\end{tabular}

\section{Perhitungan DPMO dan Six Sigma}

Rekapitulasi perhitungan DPMO dan Six Sigma dapat dilihat pada Tabel 5.

Contoh Perhitungan

a. Perhitungan DPMO

Diketahui:

Jumlah produk cacat $(\mathrm{D}) \quad=689 \mathrm{~m}$

Jumlah hasil produksi $(\mathrm{U}) \quad=807.782 \mathrm{~m}$

CTQ

$=5$

$$
\begin{aligned}
\text { Nilai DPO } & =\frac{\mathrm{D}}{\mathrm{U} \times \mathrm{CQT}} \\
& =\frac{689}{807782 \times 5} \\
& =0,00017059 \\
\text { Nilai DPMO } & =\mathrm{DPO} \times 1.000 .000 \\
& =0,00017059 \times 1.000 .000 \\
& =170,5905
\end{aligned}
$$

b. Perhitungan Sigma

$$
\begin{aligned}
\text { Sigma } & =\text { normsinv } \frac{1000000-\mathrm{DPMO}}{1000000}+1,5 \\
& =\text { normsinv } \frac{1000000-170,5905}{1000000}+1,5 \\
& =5,08
\end{aligned}
$$

\section{Kesimpulan}

Kesimpulan yang dapat diambil dari penelitian ini adalah kemungkinan penyebab cacat tertinggi yaitu pada stasiun kerja Shokki dengan nilai RPN sebesar 240. Pada stasiun kerja Shokki terjadi proses inti dalam proses produksi kain yaitu dilakukannya proses penenunan atau penganyaman kain yang berbahan benang sehingga dihasilkan hasil produksi berupa kain mentah. Kendala yang terjadi yaitu trouble mesin yang sangat berpengaruh terhadap hasil produksi. Penyebab terjadinya trouble mesin ini biasanya yaitu kesalahan dalam melakukan set up mesin dan juga kurangnya pengawasan dari operator saat proses produksi berlangsung.

Berdasarkan perhitungan nilai DPMO yang telah dilakukan didapat nilai tertinggi 181.67 yaitu pada bulan Februari 2015, artinya dalam 1.000.000 meter kain yang diproduksi terdapat sebanyak 181.67 kain yang tidak memenuhi kriteria kualitas dari PT Unitex. Sedangkan nilai Six Sigma terendah yang didapatkan yaitu sebesar 5.07 pada bulan yang sama.

Rekomendasi perbaikan terhadap pengendalian kualitas yang terpenting adalah memperkuat pengawasan kepada operator, mengutamakan pengecekan mesin, serta mementingkan ketersediaan spare part mesin terutama yang rentan mengalami kerusakan. 


\section{Daftar Pustaka}

[1] V. Mandasari and B. A. Tama, "Analisis Kepuasan Konsumen Terhadap Restoran Cepat Saji Melalui Pendekatan Data Mining: Studi Kasus XYZ," J. Generik, 2011.

[2] B. Angelova and J. Zekiri, "Measuring Customer Satisfaction with Service Quality Using American Customer Satisfaction Model (ACSI Model),” Int. J. Acad. Res. Bus. Soc. Sci., 2011.

[3] D. Meilani, P. Fithri, and P. Y. Reista, "Customer satisfaction towards product and service quality of housing developers in West Sumatra Indonesia," Int. J. Adv. Sci. Eng. Inf. Technol., vol. 8, no. 2, pp. 514519, 2018.

[4] S. AHMED, "THE EFFECTS OF MARKETING MIX ON CONSUMER SATISFACTION: A LITERATURE REVIEW FROM ISLAMIC PERSPECTIVES,” Turkish J. Islam. Econ., 2015.
[5] I. Ferreira, J. Cabral, and P. Saraiva, "An integrated framework based on the ECSI approach to link mould customers' satisfaction and product design," Total Qual. Manag. Bus. Excell., 2010.

[6] B. Nakhai and J. S. Neves, "The challenges of six sigma in improving service quality," Int. J. Qual. Reliab. Manag., 2009.

[7] D. L. Goetsch and S. Davis, Quality Management for Organizational Excellence: Introduction to Total Quality. 2014.

[8] S. Knapp, "Lean Six Sigma implementation and organizational culture," Int. J. Health Care Qual. Assur., 2015.

[9] M. M. Parast, "The effect of Six Sigma projects on innovation and firm performance," Int. J. Proj. Manag., 2011. 